\title{
Facilitating co-existence by tracking gene dispersal in conventional potato systems with microsatellite markers
}

\author{
Carloalberto PETTI ${ }^{1}$, Conor MEADE ${ }^{2}$, Martin DOWNES ${ }^{2}$ and Ewen MULLINS ${ }^{1 *}$ \\ 1 Plant Biotechnology Unit, Teagasc Crops Research Centre, Oak Park, Co. Carlow, Ireland \\ 2 Institute of Bioengineering and Agroecology, National University of Ireland, Maynooth, Co. Kildare, Ireland
}

\begin{abstract}
Based on international findings, Irish co-existence guidelines for the cultivation of GM potato stipulate that an isolation distance of $20 \mathrm{~m}$ is required to minimize the spread of transgenic pollen in accordance with required labeling thresholds. As potato tolerant to Phytophthora infestans is the most applicable GM crop from an Irish context, we tested the efficacy of this isolation distance under Irish environmental conditions using the conventional variety Désirée as a pollen donor and the male-sterile variety British Queen as a pollen receptor. Gene flow was determined by scoring for berry presence on receptor plants and confirmed using a microsatellite marker system designed to assess paternity in $F_{1}$ seedlings. $99.1 \%$ of seedlings recovered were identified as having Désirée paternity. Whereas $19.9 \%(140 / 708)$ of total berries formed on receptor plants occurred at a distance of $21 \mathrm{~m}$ from the pollen source, only 4 of these berries bore viable true potato seed (TPS), from which 23 TPS germinated. TPS-bearing berry formation was negatively correlated with distance from the pollen source, and although overall distribution of berries and seeds was non-random across the plot, no significant correlation was evident with respect to wind direction. Microsatellite markers were also used to confirm that the foraging beetle Meligethes aeneus is a vector for the transmission of potato pollen, but a more detailed statistical analysis of this dataset was limited by inclement weather during the trial. To conclude, we recommend that a two-tiered system be established in regard to establishing isolation distances for the experimental trial and commercial cultivation of GM potato in Ireland, and that responsible crop management be adopted to minimize the establishment of TPS-derived volunteers, which we have noted will emerge through a rotation as a result of pollen-mediated gene flow.
\end{abstract}

Keywords: Solanum tuberosum / potato / microsatellite / gene flow / co-existence

\section{INTRODUCTION}

Though gene flow has always been a feature of crop agroecology, the significance of the phenomenon has increased with the development and commercialization of genetically modified (GM) crops. At a European level, the subject of crop-derived gene flow is of particular relevance in regard to the debate on how GM crops are to coexist with their conventional and/or organic equivalents ('co-existence'). Establishing effective cropping regimes for co-existence that minimize both the potential and subsequent outcome of a gene flow event is a critical step to preserving the genetic integrity of existing crop systems and affording tillage farmers the opportunity to choose the tillage system (organic, conventional, GM) they wish to employ.

A crop's potential for gene flow can be quantified by assessing the four primary modes of gene dispersal:

*Corresponding author: ewen.mullins@ teagasc.ie pollen-mediated crop-to-wild relative, pollen-mediated crop-to-crop, seed-mediated crop-to-volunteer and seedmediated crop-to-feral (Flannery et al., 2005). The imposition of separation distances between GM and related non-GM crops is an accepted measure to offset the challenge pollen-mediated gene flow poses to co-existence (ACRE, 2004; Eastham and Sweet, 2002; McGill et al., 2005; Tolstrup et al., 2003). In contrast, seed-mediated gene flow presents an equal if not greater challenge to the effective management of GM crops (Flannery et al., 2005; McHughen, 2006), but measures to minimize the potential for seed-mediated gene flow are less specific, due to the current deficit in research-based support for regulators (McHughen, 2006).

We have previously published a gene flow index (GFI) model that describes the quantification of a crop's potential for both pollen and seed-mediated gene flow (Flannery et al., 2005). From this model, the composite gene flow potential of potato was calculated to be 11/27. 


\section{Petti et al.}

Considered to be high for a clonal crop, the value was weighted due to the potential for pollen-mediated cropto-crop gene flow, which can manifest during the production of true potato seed (TPS). Dependent upon the variety, the entry of TPS into the seed bank will have implications for rotational hygiene (Lawson, 1983), which in turn could have implications for crop quality and seed purity (Eastham and Sweet, 2002).

Previous studies have examined the dispersal of pollen from field-grown transgenic potatoes, and concluded that transgene dispersal is effectively limited (99.98\%) to within $10 \mathrm{~m}$ of the transgenic population (Conner and Dale, 1996; McPartlan and Dale, 1994; Tynan et al., 1990). On the contrary, a separate study reported the potential dispersal of transgenes up to $1000 \mathrm{~m}$ from the donor potato population (Skogsmyr, 1994), with an inference that the pollen beetle (Meligethes aeneus) was instrumental in facilitating gene transmission. A critical assessment of this result disputed the efficacy of the described methodology, and concluded that an isolation distance of $20 \mathrm{~m}$ was adequate to control pollenmediated transgene escape from GM potato (Conner and Dale, 1996). This conclusion was supported upon review (Eastham and Sweet, 2002) and has subsequently been adopted as a guideline to facilitate the cultivation of GM potato (Tolstrup et al., 2003).

During the compilation of the GFI model (Flannery et al., 2005) we were conscious of our reliance on international reports, due to a scarcity of Irish-specific research. Though this was especially the case for potato, we concluded that the datasets described in the peer-reviewed reports (Conner and Dale, 1996; McPartlan and Dale, 1994; Tynan et al., 1990) were applicable to Irish agronomic systems. However, the absence of national-specific datasets highlighted a need to address the issue of potatorelevant gene flow.

In the potato-based gene flow studies completed to date, the methodology employed to screen for pollenmediated gene dispersal has included screening for GUS activity (Conner, 1993; Tynan et al., 1990), NPTII enzyme assay (Conner, 1993), Southern analysis (McPartlan and Dale, 1994) and PCR (McPartlan and Dale, 1994; Skogsmyr, 1994). Co-dominant and highly polymorphic microsatellites or simple sequence repeats (SSRs) are informative genetic markers that can be employed to accurately measure pollen flow through parentage analysis (Slavov et al., 2005). As the use of SSRs circumvents the regulatory constraints associated with the cultivation of GM crops for field testing, SSRs have been used to estimate pollen-mediated gene flow for oilseed rape (Wilkinson et al., 2000), sugar beet (Andersen et al., 2005; Desplanque et al., 1999), perennial ryegrass (Ryan et al., 2007) and rice (Chen et al., 2004).
The objective of our study was to (i) calculate the frequency of pollen-mediated hybridization between two conventional potato varieties, (ii) ascertain whether the pollen beetle $M$. aeneus is a vector of pollen-mediated gene dispersal in potato and (iii) draw comparisons between our data and the existing literature. To this end we adopted a 'worst case scenario' approach that utilized the highly male-fertile Solanum tuberosum var. Désirée and the male-sterile Solanum tuberosum var. British Queen as pollen donor and receptor populations, respectively, in an experimental field trial, and screened a variety of SSR loci for their utility in tracking pollination between the two varieties.

\section{RESULTS}

\section{Flowering periods of pollen receptors and donors}

The selection of British Queen and Désirée as appropriate pollen receptor and donor populations, respectively, was based on information supplied through the European Cultivated Potato Database (see: http://www.europotato.org) and on preliminary hybridizations completed in the glasshouse. This was subsequently confirmed in the field where we conducted 45 British Queen $\times$ British Queen crosses to confirm British Queen's inability to selffertilize and control crosses (Désirée $\times$ British Queen) to confirm the ability of Désirée to pollinate British Queen (data not shown).

In the 2005 trial, the first open flowers appeared in the British Queen sub-plots 54 days post sowing (dps). The maximum number of flowering inflorescences peaked 7 to 14 days later, and flowering continued for approximately 20 further days ( $88 \mathrm{dps})$. Comparatively, the appearance of flowering inflorescences on Désirée commenced at $59 \mathrm{dps}$, and peaked between 76 and $83 \mathrm{dps}$, before concluding at $114 \mathrm{dps}$ (Fig. 1). As a result, synchronous flowering between the two varieties was recorded for over 30 days, providing adequate time to facilitate pollen-mediated hybridization should it occur. For British Queen, the total number of flowering inflorescences recorded North, South, East and West of Désirée was 2272, 2024, 1979 and 1767, respectively, with the number of Désirée flowering inflorescences estimated at 12292 for the duration of the trial.

In the 2006 trial, the flowering of the pollen receptor sub-plots mirrored that of the 2005 trial (data not shown). However, due to the late sowing dates, the flowering of both the pollen receptor and donor plots coincided with unseasonably dry conditions $\left(>30^{\circ} \mathrm{C}\right.$ for first two weeks of August). This resulted in severe damage to the maturing flower heads of the pollen donor, and as a result, the number of donor inflorescences tagged during the trial was only $2.9 \%(\mathrm{n}=359)$ of that estimated in 2005 . 
Tracking gene dispersal in potato with microsatellite markers

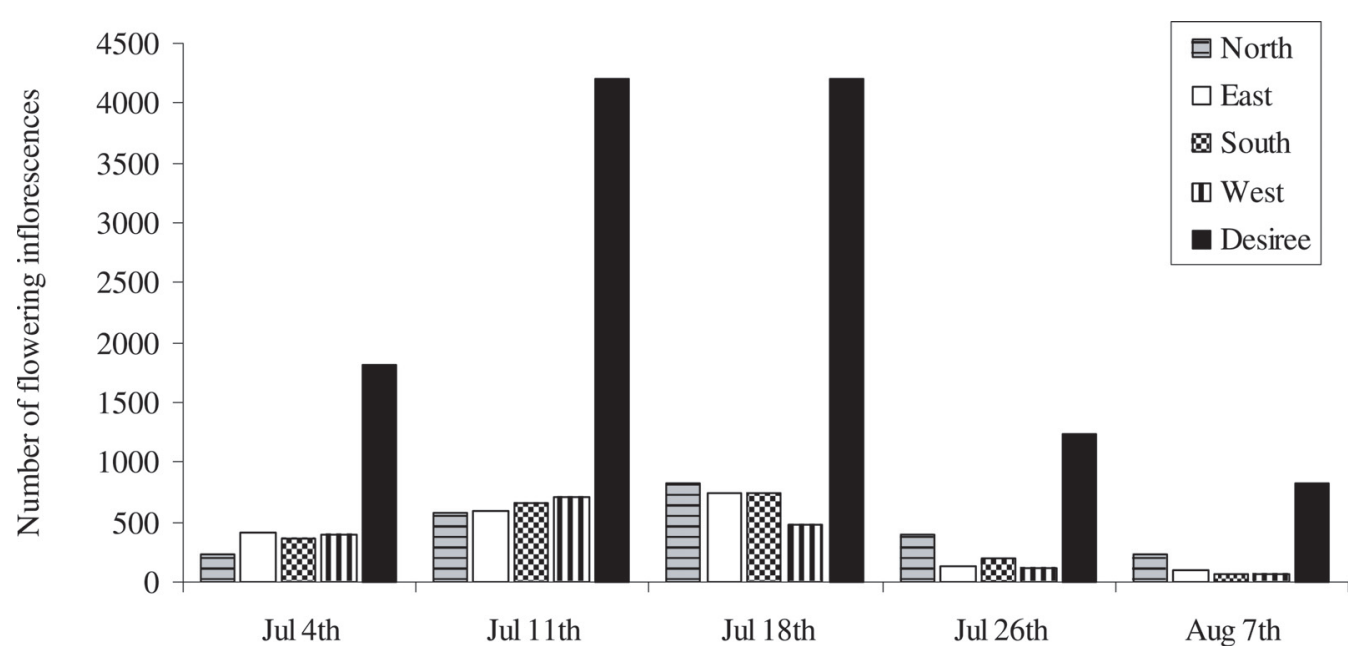

Figure 1. Flowering periods of pollen receptor (var. British Queen) sub-plots situated due North, South, East and West of the pollen donor plot (var. Désirée ) during the 2005 trial.

\section{Berry formation and TPS collection}

Berry formation was recorded on the pollen receptor sub-plots at each separation distance $(5 \mathrm{~m}, 6 \mathrm{~m}, 10 \mathrm{~m}$, $11 \mathrm{~m}, 20 \mathrm{~m}$ and $21 \mathrm{~m}$ ) across the four orientations of the 2005 trial (Fig. 2A). In total, 708 berries were collected across the trial, with 194 berries collected due North, 145 due South, 251 due East and 118 due West of the pollen donor population. During the flowering period, the prevailing winds predominated from West to South (Fig. 2B), and while this may have contributed to the increased frequency of berries collected at the North and East $(62.85 \%, \mathrm{n}=445)$ versus the South and West $(37.14 \%, \mathrm{n}=263)$ orientations, no significant correlation was evident between wind direction and berry formation.

Only $9.52 \%$ of the berries collected across the trial bore TPS (North $2.57 \%$, South $14.48 \%$, East $15.13 \%$ and West 5.93\%). Similar to the spatial distribution of berries overall on the field plot, TPS-bearing berries showed a non-random distribution with respect to compass orientation from the pollen source that was not correlated with wind direction. However, when the frequency of TPSbearing berries was pooled for each distance across the trial, a significant negative association was observed with increased distance from the perimeter of the pollen source $\left(\mathrm{R}^{2}=0.749, \mathrm{P}<0.05\right)$.

Of the 1288 TPS that were recovered from the trial, only $774(60.1 \%)$ grew sufficiently to provide adequate tissue for DNA extraction and subsequent genotyping. Regression analysis confirmed negative associations between both the recovery $\left(\mathrm{R}^{2}=0.67, \mathrm{P}<0.05\right)$ and germination of TPS $\left(\mathrm{R}^{2}=0.722, \mathrm{P}<0.05\right)$ with respect to increased distance from the donor population; however
TPS occurrence and germination were sporadic within each orientation (Tab. 1).

As a consequence of the reduced incidence of flowering in the 2006 trial, berry formation and subsequent TPS recovery was not anticipated. However, 25 berries were collected from the pollen receptor sub-plots. Comparable to $2005,8 \%(\mathrm{n}=2$, one from $20 \mathrm{~m}$ East and one from $5 \mathrm{~m}$ West) bore TPS, from which 38 TPS were harvested. 11 seeds subsequently germinated and provided adequate tissue for genotyping.

\section{Genotyping the $F_{1}$ populations}

Of the 24 SSRs initially tested, only the polymorphic St5130, St5136, St5148 and St0019 loci presented variety-specific alleles (two from St5130 and one each from St5136, St5148 and St0019) that could effectively distinguish between the Désirée and British Queen genotypes (Tab. 2).

Application of these four SSR markers to genotype the $F_{1}$ population $(n=774)$ identified $99.1 \%(n=767)$ of the population as possessing Désirée-specific alleles (Fig. 3). Seventy-six hybrids (9.8\%) of the $F_{1}$ population possessed a single diagnostic allele, 200 (25.8\%) displayed two alleles, $282(36.4 \%)$ possessed three alleles, $167(21.5 \%)$ recorded four alleles and $42(5.4 \%)$ possessed all five alleles. The remaining $0.9 \%$ of the hybrid population corresponded to seven $\mathrm{F}_{1}$ individuals for which the SSR system was not adequately diagnostic to effectively genotype. SSR-based analysis of the hybrid population $(n=11)$ derived from the 2006 trial confirmed their paternity, as each had at least one of the five available Désirée marker alleles. 
A
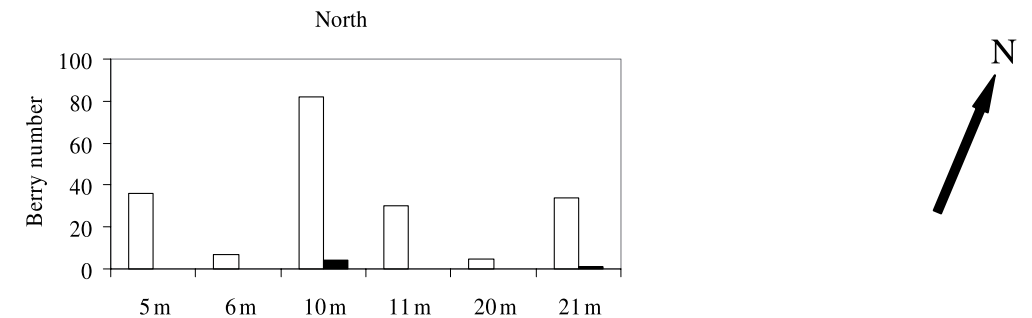

West
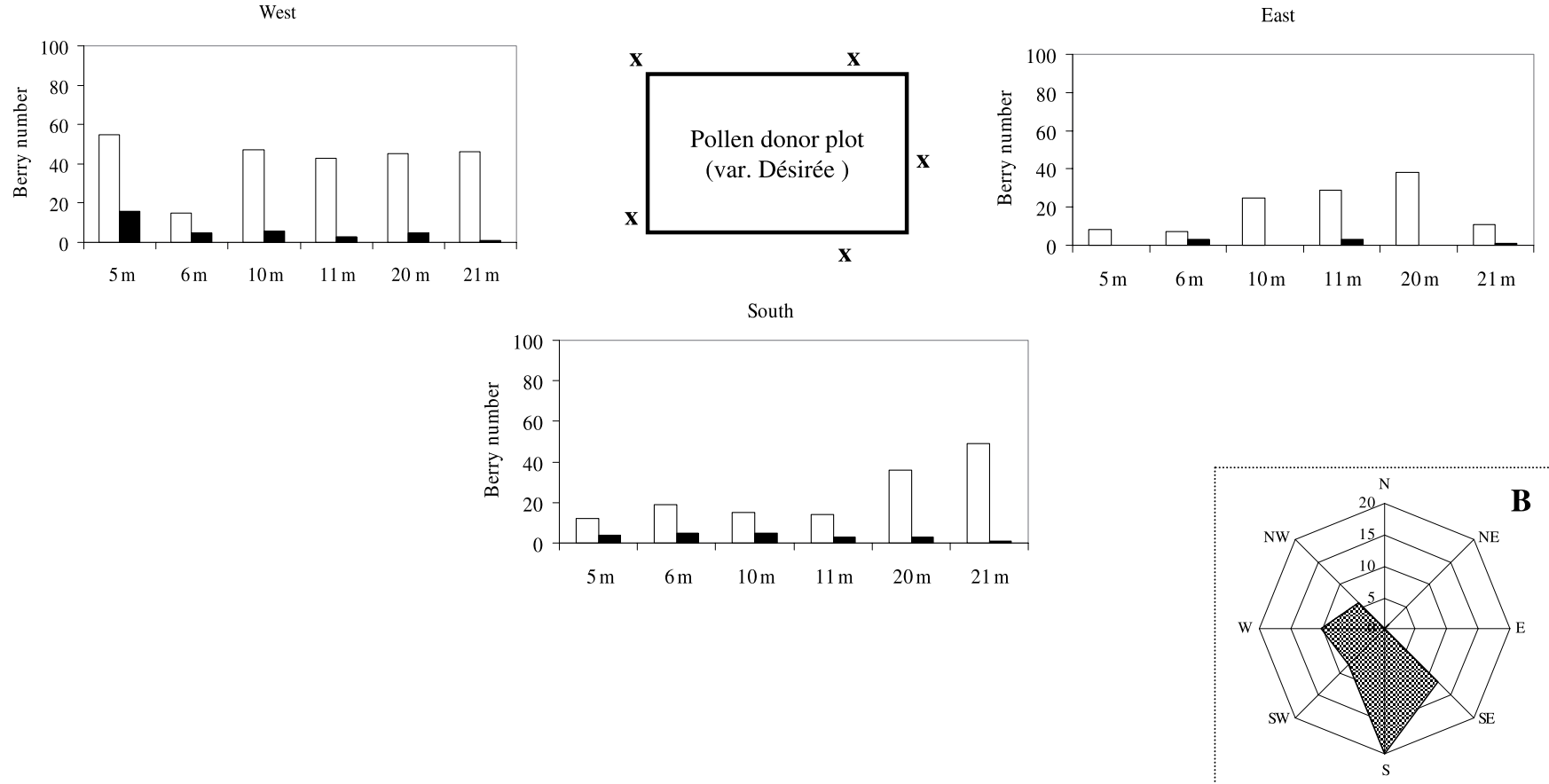

Figure 2. A. Distribution of berries ( $\square$ ) and berry-bearing true potato seed ( $\mathbf{\square}$, TPS) across pollen receptor sub-plots (var. British Queen) at distances of $5 \mathrm{~m}, 6 \mathrm{~m}, 10 \mathrm{~m}$, $11 \mathrm{~m}, 20 \mathrm{~m}$ and $21 \mathrm{~m}$ at the North, South, East and West orientation of the pollen donor plot (var. Désirée). In 2006, the footprint of each original receptor sub-plot was surveyed for TPS-derived volunteers, in addition to 5 locations $(\times)$ around the pollen donor plot. B. Prevailing wind direction (shaded) in days $(0-20)$ during synchronous flowering period (July 4th-August 7th, 2005). 
Tracking gene dispersal in potato with microsatellite markers

Table 1. Number of true potato seed (TPS) that were recovered (recov.) and subsequently germinated (germ.). TPS was collected from berries that formed on pollen receptors (var. British Queen) at separation distances of $5 \mathrm{~m}, 6 \mathrm{~m}, 10 \mathrm{~m}, 11 \mathrm{~m}, 20 \mathrm{~m}$ and $21 \mathrm{~m}$ for each of the four orientations, North, South, East and West of the pollen donor (var. Désirée) central plot. \% germination presented in brackets.

\begin{tabular}{lcccccccccccc}
\hline & \multicolumn{10}{c}{ Separation distance } \\
\hline & \multicolumn{1}{c}{$5 \mathrm{~m}$} & \multicolumn{2}{c}{$6 \mathrm{~m}$} & \multicolumn{2}{c}{$10 \mathrm{~m}$} & \multicolumn{2}{c}{$11 \mathrm{~m}$} & \multicolumn{2}{c}{$20 \mathrm{~m}$} & \multicolumn{2}{c}{$21 \mathrm{~m}$} \\
\hline & TPS & TPS & TPS & TPS & TPS & TPS & TPS & TPS & TPS & TPS & TPS & TPS \\
& recov. & germ. & recov. & germ. & recov. & germ. & recov. & germ. & recov. & germ. & recov. & germ. \\
\hline North & 0 & 0 & 0 & 0 & 28 & 16 & 0 & 0 & 0 & 0 & 22 & 0 \\
South & 110 & 73 & 74 & 47 & 57 & 52 & 77 & 62 & 123 & 66 & 13 & 12 \\
East & 0 & 0 & 45 & 34 & 0 & 0 & 73 & 59 & 0 & 0 & 23 & 6 \\
West & 260 & 109 & 142 & 84 & 126 & 86 & 34 & 25 & 76 & 57 & 5 & 5 \\
Total & 370 & 182 & 261 & 165 & 211 & 154 & 184 & 146 & 199 & 123 & 63 & 23 \\
& & $(49.1 \%)$ & & $(63.2 \%)$ & & $(72.98 \%)$ & & $(79.34 \%)$ & & $(61.8 \%)$ & $(36.5 \%)$ \\
\hline
\end{tabular}

Table 2. Details of S. tuberosum SSR loci with the ability to distinguish between Désirée and British Queen genotypes.

\begin{tabular}{|c|c|c|c|c|}
\hline Locus name & $\begin{array}{l}\text { Primer sequence } \\
\left(5^{\prime}-3^{\prime}\right)\end{array}$ & $\begin{array}{l}\text { Annealing } \\
\text { temp. }\left({ }^{\circ} \mathrm{C}\right)\end{array}$ & $\begin{array}{l}\text { Average size } \\
\text { of alleles (bp) }\end{array}$ & Allele size (bp) \\
\hline \multirow[t]{2}{*}{ STM0019 } & F: AAT AGG TGT ACT GAC TCT CAA TG & 55 & 200 & $194.21,203.05,229.86(\mathrm{BQ})$ \\
\hline & R: TTG AAG TAA AAG TCC TAG TAT GTG & & & 188.38, 203.32, 229.91 (Des) \\
\hline \multirow[t]{2}{*}{ STM5130 } & F: AAA GTA CAG CGA AGA TGA CGA C & 55 & 260 & $254.73,257.42(\mathrm{BQ})$ \\
\hline & R: TTA CCT TTG CAA CCT TGC C & & & $248.50,254.82,257.47,260.73$ (Des) \\
\hline \multirow[t]{2}{*}{ STM5136 } & F: GGG AAA AGG AAA AGC TCA A & 60 & 240 & $215.89,224.43,245.04(\mathrm{BQ})$ \\
\hline & R: TAT ATG AAC CAC CTC AGG CAC & & & $224.44,227.54,245.00$ (Des) \\
\hline \multirow[t]{2}{*}{ STM5148 } & F: TCT TCT TGA TGA CAG CTT CG & 60 & 450 & $443.57,449.04,469.07$ (BQ) \\
\hline & R: ACC TCA GAT AGT TGC CAT GTC A & & & $414.83,443.62,449.02$ (Des) \\
\hline
\end{tabular}

\section{Morphological analysis of $F_{1}$ populations}

The value of utilizing the heritable morphological trait of tuber color as a dominant genetic marker for gene flow in potatoes has already been highlighted (Conner and Dale, 1996). To complement the SSR-based data sets collated from the 2005 trial, the $F_{1}$ plantlets were allowed to senesce and tuberize in the glasshouse. Of the 74 hybrids, 715 individuals formed tubers. Within this population the segregation of tuber color (yellow:red) for hybrids derived from each separation distance (and pooled within each orientation) was recorded as 95:74 at $5 \mathrm{~m}, 70: 78$ at $6 \mathrm{~m}, 76: 57$ at $10 \mathrm{~m}, 52: 73$ at $11 \mathrm{~m}, 57: 61$ at $20 \mathrm{~m}$ and 8:14 at $21 \mathrm{~m}$. This equated to the expected 1:1 segregation ratio, with 357 progeny possessing red-skinned tubers and 358 retaining the British Queen-associated yellow skin. Notably, the seven unidentified hybrids that did not amplify specific SSR profiles (see above) did form tubers with red skins, hence confirming their hybrid status and Désirée parentage.

\section{Survey of $M$. aeneus populations}

A previous report has provided anecdotal evidence to suggest that the foraging beetle $M$. aeneus can serve as a pollinator for potato (Skogsmyr, 1994). We considered this in the context of the sporadic nature of hybridization observed in the 2005 trial, and hypothesized that a proportion of the gene dispersal recorded was mediated via $M$. aeneus. To this end, we surveyed for the presence of $M$. aeneus on the pollen-receptor flowers of each distance (per orientation) of the 2006 trial. Of the 106 pooled beetle samples (taken over the 28-day sampling period), 23 tested positive for the presence of Désirée-specific alleles (Fig. 4A, SSR analysis in Fig. 3), confirming that the beetle had indeed assisted in the transmission of pollen from the pollen donor to the pollen receptor sub-plots. Though bumblebee activity was observed across the plot at flowering, it was infrequent, and observations noted that the bees resided principally within the Désirée plot and tended to avoid the British Queen plants.

Across the 23 positive pooled beetle samples, a median of three beetles per pooled sample with a maximum of 10 and minimum of one beetle was recorded. The distribution of these gene dispersal events across the trial site was neither orientation nor distance-specific (Fig. 4B) and there was no significant association between detection and distance from the pollen source across the trial $(\mathrm{P}>0.05)$. While the result confirmed the role of M. aeneus as a vector for gene dispersal in potato, it was noteworthy that no correlation was observed between the number of pooled beetles collected and the occurrence of 


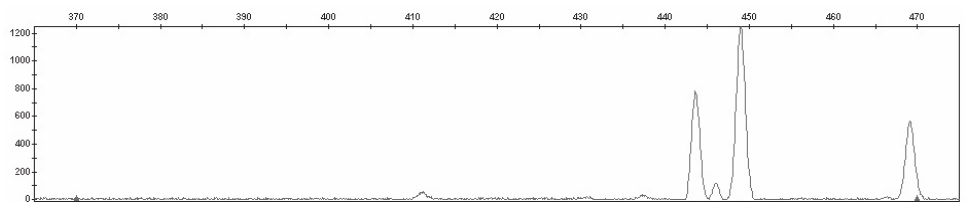

St 5148

British Queen

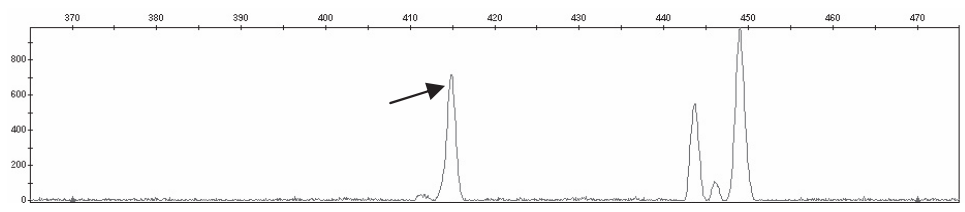

St 5148

Désirée

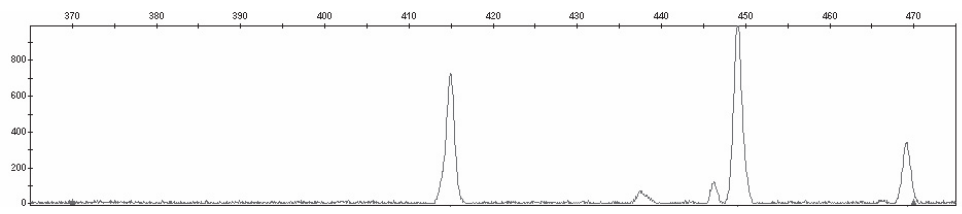

St 5148

E4-4 hybrid

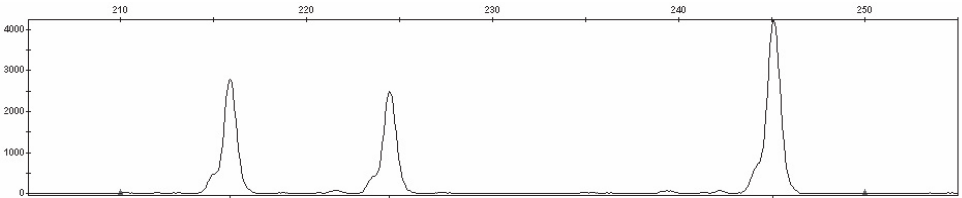

St 5136

British Queen

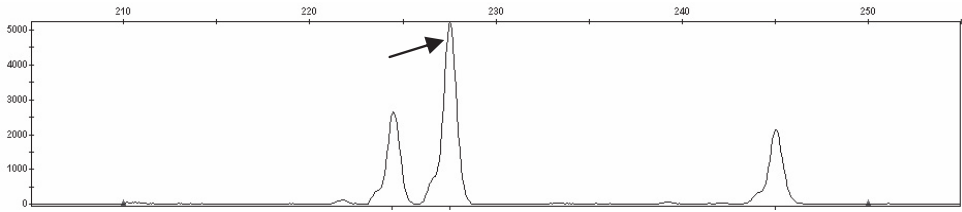

St 5136

Désirée

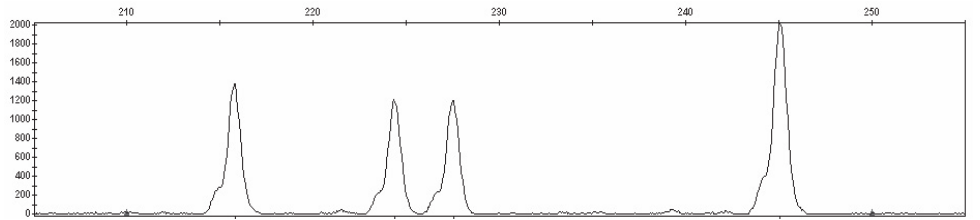

St 5136

W3-2 hybrid

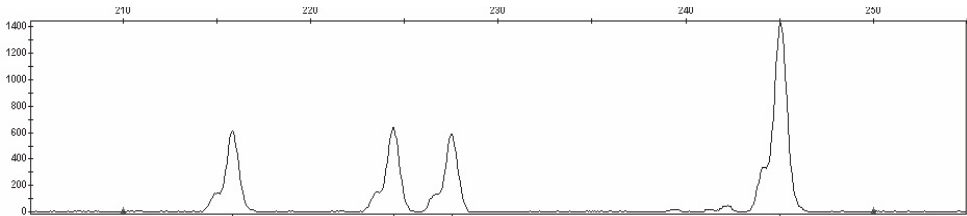

St 5136

E4-14 beetle

Figure 3. SSR allele profiles in British Queen (pollen receptor), Désirée (pollen donor), their associated hybrids (E4-4, W3-2, N4-34 and S3-13) and a pooled M. aeneus beetle sample (E4-14), at the St5148, St5136, St5130 and St0019 loci. Only the St5136 and St5130 loci were assayed in regard to the pooled beetle sample. Arrows indicate the variety-specific alleles diagnostic for the pollen donor. 




St 5130

British Queen



St 5130

Désirée

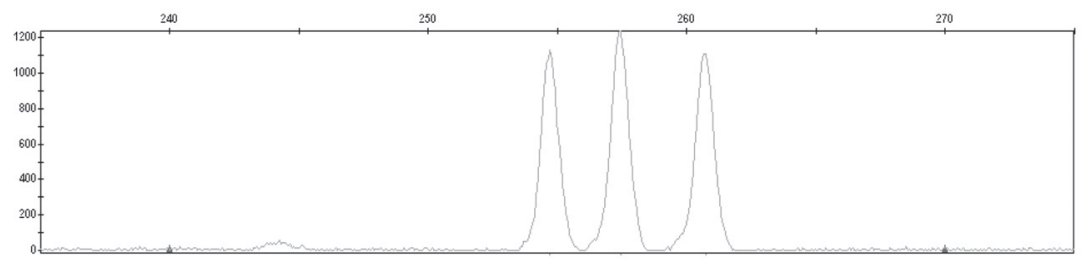

St 5130

N4-34 hybrid



St 5130

E4-14 beetle



St 0019

British Queen

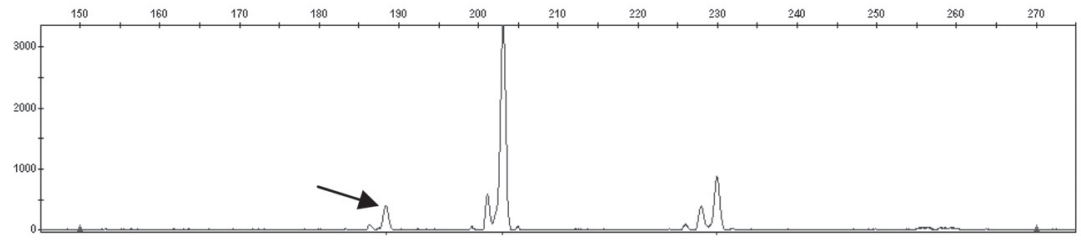

St 0019

Désirée

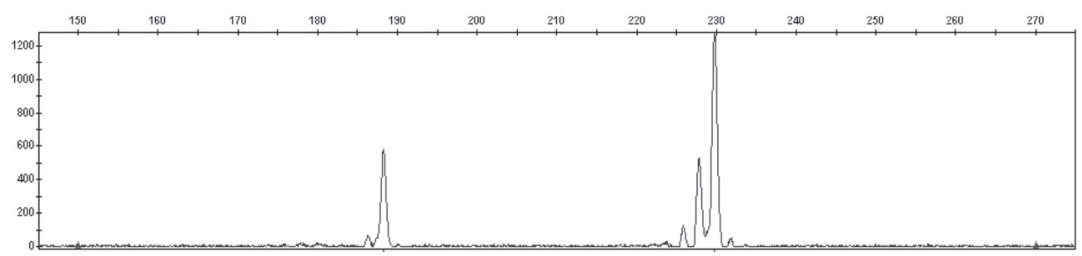

St 0019

S3-13 Hybrid

Figure 3. Continued. 


\section{Petti et al.}



B
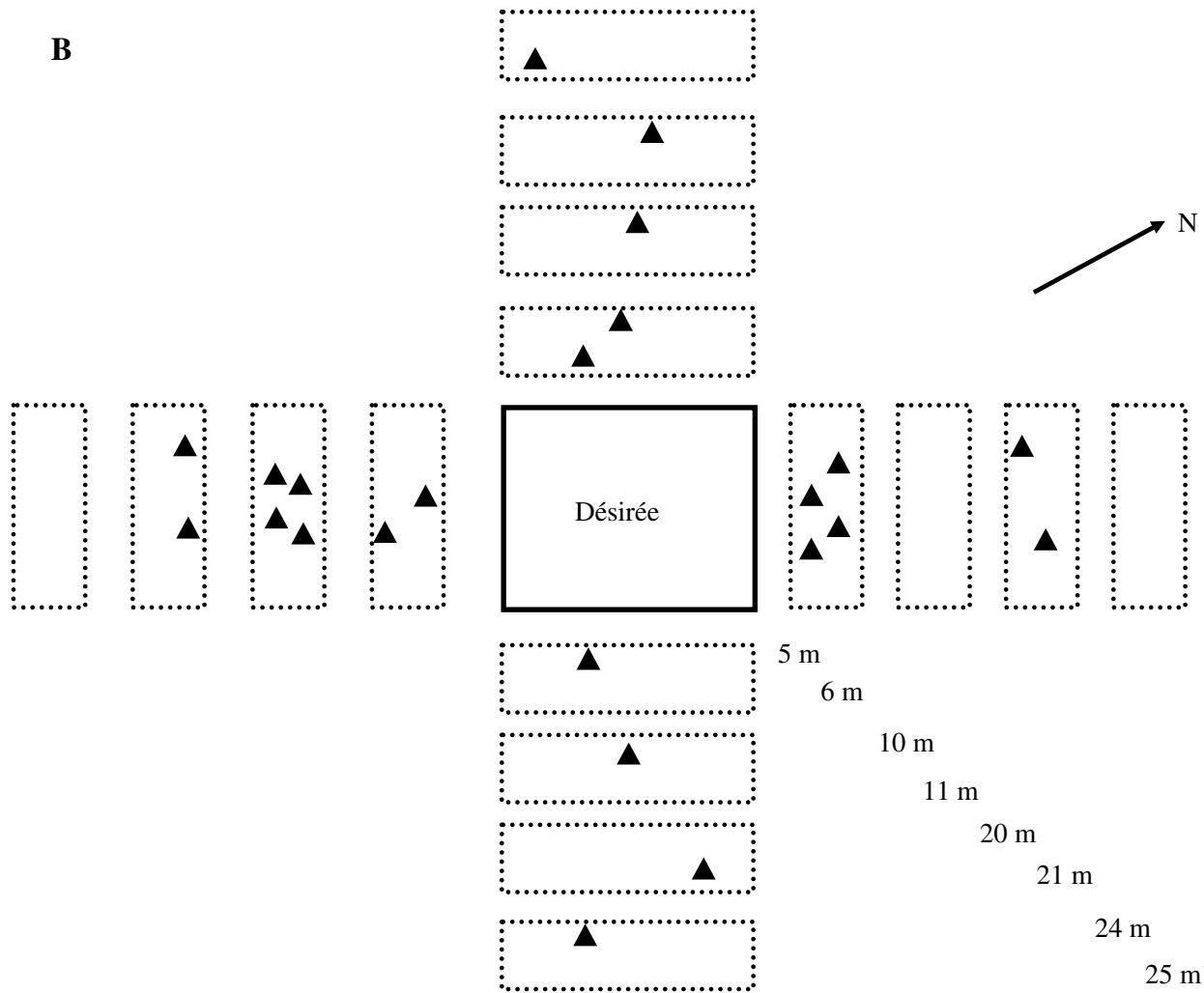

Figure 4. A. Incidence of pooled M. aeneus samples collected from pollen receptor (var. British Queen) flowers that tested positive for Désirée-specific alleles (SSR positive) via SSR analysis relative to the number of pooled samples collected over the sampling period. B. M. aeneus-mediated distribution of Désirée pollen across the pollen receptor (var. British Queen) sub-plots of the 2006 trial site. Each $(\boldsymbol{\Lambda})$ represents the location of a receptor flower from which a pooled beetle sample was collected and tested positive for Désirée-specific alleles. 
Tracking gene dispersal in potato with microsatellite markers

pooled beetles possessing Désirée-specific alleles $(\mathrm{P}>$ 0.05 ) during the 4-week sampling period.

\section{Monitoring TPS-derived volunteers}

During the summer of 2006, the 2005 trial site was revisited and a survey for TPS-derived volunteers was completed. As expected, a high number of TPS-derived volunteers (average of 324 per $\mathrm{m}^{2}$ ) were recorded around the original pollen donor plot (Fig. 1) due to the high fertility of Désirée. In contrast, 30 TPS-derived volunteers were located around the combined footprints of the original pollen receptor (cv. British Queen) sub-plots. SSR analysis confirmed that $90 \%(n=27)$ of this volunteer population possessed a Désirée genotype, highlighting the potential for machinery-based transfer of potato seed. The remaining three volunteers were hybrids between British Queen and Désirée.

\section{DISCUSSION}

In 2005 we established a work program to clarify several biosafety issues in regard to the predicted cultivation of GM potatoes in Ireland. In light of the strong evidence presented in previous reports on pollen-mediated gene flow our objective was to:

1. verify the effectiveness of existing separation distances to minimize pollen-mediated gene flow in a field environment;

2. ascertain the potential of M. aeneus as a vector for gene transmission in potato.

Our system was similar in design to a previously published field trial (McPartlan and Dale, 1994) but we utilized two conventional potato varieties, and relied on an SSR-based system to score for successful gene flow events between the pollen donor and receptor sub-plots. Adopting a 'worst case scenario' system, our results indicate both that pollen-mediated gene flow in potato can extend upwards of $21 \mathrm{~m}$ from the pollen donor population and that M. aeneus is a carrier of potato pollen. Adverse weather conditions undermined the 2006 trial and thus our gene flow data (berry number and TPS occurrence) are primarily based on results from the 2005 experiment. While we acknowledge that this truncated dataset is far from ideal, on review of the results we believe that important findings are evident from the existing data.

To facilitate hybridization between the male-sterile receptor (cv. British Queen) and pollen donor (cv. Désirée) plots, we staggered the sowing of both populations, which led to a period of synchronous flowering in excess of 30 days. The SSR-based detection system that we have described, and substantiated by screening for tuber color in the $F_{1}$ population, proved to be an effective tool with which to trace field-based hybridization between two potato varieties (Fig. 3). While AFLPs have been employed to study gene flow between potato species (Celis et al., 2004), to our knowledge this is the first report of using SSRs for this purpose in potato. Furthermore, employing the same system to trace insectmediated pollen transfer between the donor and receptor individuals confirms the versatility of microsatellite markers in recovering gene flow data that may prove important for addressing biosafety issues.

While the thematic novelty of our experiment remains in the re-evaluation of the separation distances and the demonstration that SSRs are a very effective technique with which to monitor both wind- and insect-mediated gene flow in potato, it is critical that the interpretation of these findings remains in context in order to assist future co-existence strategies. By using male-sterile receptors we intentionally biased our experiment in order to maximize the possibility for hybridization, hence adopting a 'worst case scenario' approach that does have a tendency to over-estimate the level of gene flow. However, even under these circumstances, while we achieved substantial berry formation $(n=140)$ at distances in excess of $20 \mathrm{~m}$, only $2.8 \%(\mathrm{n}=4)$ of these berries contained seed of which only $36 \%(n=23)$ germinated.

In the context of co-existence management it is important to consider whether these individuals are likely to survive in the field. Our results clearly indicate that TPS-based volunteers will emerge through a rotation over time. In addition, our results highlight the potential for the machinery-based transfer of TPS within the field. However, it is important to note that the 2005 trial site remained fallow over the winter to purposefully encourage volunteer emergence. So while we concur with previous reports (Lawson, 1983) that highlight the potential of TPS-derived volunteers to challenge efficient crop management (as manifested in our trial with the emergence of 30 TPS-based volunteers), we believe the issue can be negated through vigilant crop management and appropriate rotations. As such the emergence of TPS-based volunteers should pose no threat to the effective co-existence of GM and non-GM potato crops, assuming appropriate crop stewardship has been adopted.

Applying the SSR assay to M. aeneus individuals collected from pollen receptor flowers provided an insight into an alternative mode of gene transmission in potato and presented a possible explanation for the irregular pattern of hybridization observed in the 2005 field evaluation. While our research indicates the possibility that individual hybridization events could occur over greater distances as previously suggested (Skogsmyr, 1994). We believe that $M$. aeneus-mediated gene dispersal will not present a consistent challenge to co-existence based on 


\section{Petti et al.}

our survey results (Figs. 4A and 4B), but rather will account for haphazard pollination events that will be dependent upon the travel circumference of the beetle. If a higher degree of containment were required for a specific transgenic potato, the application of insecticide at flowering and/or the planting of bait crops around the periphery of the transgenic potato crop could be considered.

Current guidelines on co-existence relate to maintaining the degree of GM admixture in non-GM material below the $0.9 \%$ threshold (Recommendation 2003/556/EC) and it is based on this level that we make our conclusions. In their consideration of previously published data on pollen dispersal from field trials of transgenic potato, Conner and Dale (1996) concluded that $20 \mathrm{~m}$ was adequate for initial field evaluations. Based on our experience and taking into account (i) our intentional use of male-sterile receptors, (ii) the isolation of our trial from other sites of potato cultivation, (iii) the clonal nature of potato and significantly (iv) the fact that the release of GM potatoes will involve plants hemizygous for the transgene which implies a 1:1 segregation of pollen with and without the transgene, we advocate that a twotiered system be established for any future cultivation of transgenic potato in Ireland. For the cultivation of male-fertile GM potato under a Class B license (precommercialization trial), we recommend that to minimize the potential and outcome of pollen-mediated gene flow, the trial should be:

- isolated from adjacent sites of potato cultivation by a minimum of $30 \mathrm{~m}$;

- rotated through ryegrass to facilitate the recording of TPS-derived volunteer emergence and establishment prior to burning off with herbicide;

- and that both male-sterile and male-fertile bait plants are established at larger distances (e.g. 200-300 m) from the trial to gauge the degree of insect-mediated transfer of transgenic pollen from the site.

Pending results from the Class B trials and additional risk analysis as in accordance with Directive 2001/18 (EC), we recommend that for the commercial cultivation of GM potato and its co-existence with non-GM tillage systems:

- an isolation distance of $20 \mathrm{~m}$ is adequate to limit gene dispersal in accordance with EU labeling thresholds;

- responsible crop management is practiced in regard to the control of TPS-derived volunteers and groundkeepers through the rotation.

We acknowledge that our recommendation of 30 m may seem excessive, based on previous literature and the data presented here, and as such could be perceived to be more policy-driven than science-based. However, we believe it is a responsible approach in light of the current negativity towards GM trials, and while conservative it is not excessive, and should be adopted to alleviate societal concern in regard to the research-based (Class B license) trials of GM potato. Significantly, by recommending unique isolation distances based on the Class of license, an opportunity is still provided to lower the distance if the environmental risk assessments conducted during the Class B cultivation support such an approach. Quite simply, a $30 \mathrm{~m}$ separation distance should be seen as the best estimate for the pre-commercialization testing of GM potatoes in Ireland.

A condition of the recent license granted for the Class $\mathrm{B}$ cultivation of transgenic blightresistant potato in Ireland, related to the removal of berries formed during the course of the trial (http://www.epa.ie/Licensing/GMOLicensing/). It is important to note that it is only TPS germination and ultimately the establishment of volunteers within the rotation that will pose an issue for co-existence and not simply the occurrence of berries. This distinction between the potential for gene flow and the outcome of a gene flow event is often overlooked and can generate an unnecessary workload when standard tillage operations (e.g. minimum tillage and application of systemic herbicide) would otherwise adequately control TPS-derived volunteers.

To date, 256 notifications for the Class B (precommercial) release of transgenic potato have been submitted to the various competent authorities of the European Union's member states (http://biotech.jrc.it/deliberate/dbplants.asp). Eight of these submissions relate to the experimental release of transgenic potato with improved resistance to potato blight ( $P$. infestans), which is a much desired agronomic trait of significant economic potential in Ireland (Flannery et al., 2005). As the potential economic benefit of cultivating a blight-resistant potato line becomes more apparent to potato growers, it is reasonable to assume that it will be the larger producers who will initially decide to adopt the technology (Fernandez-Cornejo et al., 2001) due to the reduced cost base, but also because of the increased convenience factor associated with GM crop cultivation, which could appeal greatly to Ireland's part-time farmers ( 48\%, http://www.teagasc.ie/). If this scenario is to occur, preserving the genetic identity of non-GM cropping systems will be crucial. Central to this will be the establishment of effective co-existence measures through the completion of region-specific research studies. From an applied perspective, we believe that the research outlined here will clarify several issues that have been raised by regulators in regard to the cultivation of GM potato in Ireland. From a scientific perspective, our study confirms that both wind- and insect-mediated gene flow in potato can be assessed using microsatellite markers. 
Tracking gene dispersal in potato with microsatellite markers

\section{MATERIALS AND METHODS}

\section{Plant material and field trial design}

The criteria required for selecting the appropriate varieties for the trial included: (i) a high propensity for flowering for both pollen donor and receptor, and (ii) high male fertility for the donor and corresponding male sterility in the receptor. Based on agronomic data collated through the European Cultivated Potato Database (see: http://www.europotato.org), the potato varieties Désirée and British Queen were adopted as the pollen donor and receptor, respectively. Non-transgenic seed tubers of both varieties were obtained from the Teagasc Potato Breeding program at Oak Park, and preliminary hybridizations were conducted under glasshouse conditions to confirm the compatibility of the Désirée male-fertile and British Queen male-sterile genotypes. In 2005, these varieties were incorporated into a field plot design comparable in design to a previously published experiment (McPartlan and Dale, 1994).

Désirée tubers were sown into 20 drills (approximately 50 tubers/drill) in the central plot $(17 \mathrm{~m} \times 17 \mathrm{~m})$ with $85 \mathrm{~cm}$ separation distance between each drill, and approximately $35 \mathrm{~cm}$ between each tuber within a drill. Pollen receptor drills were orientated North, South, East and West of the central plot and at distances of $5 \mathrm{~m}, 6 \mathrm{~m}$, $10 \mathrm{~m}, 11 \mathrm{~m}, 20 \mathrm{~m}$ and $21 \mathrm{~m}$ from the nearest edge of the Désirée population. Sown with British Queen tubers (approximately 30 tubers/drill), each drill was $10 \mathrm{~m}$ in length.

To ensure synchronous flowering of both varieties, Désirée was sown two weeks (April 26th, 2005) prior to the early maturing British Queen (May 11th, 2005). The plot was isolated by at least $300 \mathrm{~m}$ from any other site of potato cultivation, and the trial crop was treated as a commercial potato crop in regard to the application of fertilizer and fungicide to offset $P$. infestans.

Arising from the results obtained from the 2005 trial, the trial was repeated in 2006 on a separate site. Again, pollen receptor beds were orientated North, South, East and West of the central plot at distances $5 \mathrm{~m}, 6 \mathrm{~m}, 10 \mathrm{~m}$, $11 \mathrm{~m}, 20 \mathrm{~m}$ and $21 \mathrm{~m}$ from the nearest edge of the Désirée population, with additional drills sown at $24 \mathrm{~m}$ and $25 \mathrm{~m}$ for each orientation (Fig. 4B). Due to excessively wet conditions during April and May, Désirée and British Queen were not sown until the first and second week of June respectively. Similar to the 2005 trial, the site was managed as a commercial crop and remained isolated $(>800 \mathrm{~m})$ from other sites of potato cultivation.

\section{Field data collection and true potato seed treatment}

The frequency of flowering on the pollen receptor subplots was recorded at weekly intervals by noting the number of inflorescences that had at least one fully opened flower. To prevent duplication, each inflorescence was subsequently tagged. Due to the density of the Désirée crop canopy, the frequency of flowering was conservatively estimated by recording an average of the number of inflorescences appearing on the two external drills (West and East side) of the Désirée plot.

Berry collection from the British Queen drills was conducted at 2-day intervals. For each distance (at each orientation) mature berries were harvested, and the TPS that was collected from each berry was washed, dried and stored at $4{ }^{\circ} \mathrm{C}$. After 12 weeks, TPS were surfacesterilized and sown on MS basal media (Murashige and Skoog, 1962). Seedlings were transferred to compartmentalized trays containing potting compost, and cultivated in the glasshouse at $22^{\circ} \mathrm{C}$ using a $16 \mathrm{~h}$ light and $8 \mathrm{~h}$ dark cycle, before tissue was collected for DNA extraction.

The incidence of the pollinator $M$. aeneus across the 2006 trial site was recorded over a 28-day period. For each sampling date, pollen receptor (var. British Queen) flowers were surveyed, and collected beetles were pooled for each distance (per orientation). In total, 106 pooled samples were processed for subsequent DNA extraction and SSR analysis.

\section{Plant and insect DNA extraction and SSR analysis}

Mechanical tissue disruption was completed on freezedried leaves or flash frozen (in liquid $\mathrm{N}_{2}$ ) pooled beetles using a mixer mill (Retsch MM300). DNA extraction was completed using a modified CTAB method that was adapted for $2 \mathrm{ml}$ eppendorf tubes. Modifications included increasing the final concentration of $\mathrm{NaCl}(2 \mathrm{M})$ and extending the duration of the chloroform:isoamyl alcohol (24:1) extraction to $60 \mathrm{~min}$, with the final precipitation completed at room temperature.

To identify the paternity of each $\mathrm{F}_{1}$ hybrid, we developed an SSR-based genotyping system. SSR-polymerase chain reaction (SSR-PCR) was completed in $20 \mu \mathrm{L}$ reactions containing: $40 \mathrm{ng}$ TPS DNA and to a final concentration, dNTPs $(200 \mu \mathrm{M}), \mathrm{MgCl}_{2}(2.5 \mu \mathrm{M})$, BSA (50 $\left.\mu \mathrm{g}\right)$, forward and reverse primers $(250 \mathrm{nM})$. In total, $24 \mathrm{SSR}$ primer pairs (details not shown) were selected from the literature (Ghislain et al., 2004; Milbourne et al., 1998) and tested for their ability to distinguish between Désirée and British Queen genotypes. For genotyping, the forward primer of each pair was labeled with a florescent dye (Vic, Ned, Pet or 6-FAM, Applied BioSystems, California, USA). For the SSR-PCR, conditions included $95^{\circ} \mathrm{C}$ for $10 \mathrm{~min}, 9$ cycles of $94^{\circ} \mathrm{C}$ for $60 \mathrm{~s}, 65^{\circ} \mathrm{C}$ for $30 \mathrm{~s} \mathrm{de}$ creasing $1{ }^{\circ} \mathrm{C} /$ cycle, $72{ }^{\circ} \mathrm{C}$ for $60 \mathrm{~s}, 24$ cycles of $94{ }^{\circ} \mathrm{C}$ for $30 \mathrm{~s}, 55^{\circ} \mathrm{C}$ for $30 \mathrm{~s}, 72{ }^{\circ} \mathrm{C}$ for $30 \mathrm{~s}$, completed with $72{ }^{\circ} \mathrm{C}$ for $10 \mathrm{~min}$. SSR-PCR amplicons were genotyped 


\section{Petti et al.}

on an ABI3100 platform (Applied Biosystems, California USA), with allele analysis completed using ABI Gene Mapper v3.7.

\section{Morphological assessment of hybrid population}

The value of utilizing the heritable morphological trait of tuber color as a dominant genetic marker for gene flow in potatoes has already been highlighted (Conner and Dale, 1996). To complement the SSR-based data sets collated from the 2005 trial, the $F_{1}$ plantlets were allowed to senesce and tuberize in the glasshouse. From the initial $F_{1}$ population $(n=774), 715$ individuals developed tubers (after 8-10 weeks) and these were scored for the recessive yellow skin color (aaa) associated with British Queen, or for the single dominant allele genotype (Aaaa) that is characteristic of Désirée.

\section{Survey of TPS-derived volunteers}

After leaving the 2005 trial site fallow over the winter, the establishment of TPS-derived volunteers was studied in June 2006 by surveying the footprint of each of the original pollen receptor sub-plots, in addition to five locations around the original pollen donor plot (Fig. 1).

\section{ACKNOWLEDGEMENTS}

The authors wish to thank Susanne Eivers for her assistance during the field work of 2005, Toni Wendt for his assistance with the SSR analysis and Dr. Dan Milbourne for his suggestions during the compilation of the paper. Ewen Mullins and Carlo Petti were funded through the Irish National Development Plan (2000-2006). Conor Meade was funded by the Department of Agriculture and Food Research Stimulus Fund, through the National Development Plan (2000-2006).

Received December 19, 2006; accepted 8 May, 2007.

\section{REFERENCES}

ACRE (2004) Advice on scientific issues concerning the proposed regime for the co-existence of GM and non-GM crops, p 6. U.K. Advisory Committee on Releases to the Environment, Department for Environment, Food and Rural Affairs

Andersen NS, Siegismund HR, Meyer V, Jorgensen RB (2005) Low level of gene flow from cultivated beets (Beta vulgaris $L$. ssp. vulgaris) into Danish populations of sea beet (Beta vulgaris L. ssp. maritima (L.) Arcangeli). Mol. Ecol. 14: 1391-1405
Celis C, Scurrah M, Cowgill S, Chumbiauca S, Green J, Franco J, Main G, Kiezebrink D, Visser RGF, Atkinson HJ (2004) Environmental biosafety and transgenic potato in a centre of diversity for this crop. Nature 432: 222-225

Chen LJ, Lee DS, Song ZP, Suh HS, Lu B-R (2004) Gene flow from cultivated rice (Oryza sativa) to its weedy and wild relatives. Ann. Bot. 93: 67-73

Conner AJ (1993) Monitoring "escapes" from field trials of transgenic potatoes: a basis for assessing environmental risks. In Seminar on Scientific Approaches for the Assessment of Research Trials with Genetically Modified Plants, OECD, Paris, pp 34-40

Conner AJ, Dale PJ (1996) Reconsideration of pollen dispersal data form field trials of transgenic potatoes. Theor. Appl. Genet. 92: 505-508

Desplanque B, Boudry P, Broomberg K, SaumitouLaprade P, Cuguen J, Van Dijk H (1999) Genetic diversity and gene flow between wild, cultivated and weedy forms of Beta vulgaris L. (Chenopodiaceae), assessed by RFLP and microsatellite markers. Theor. Appl. Genet. 98: 1194-1201

Eastham K, Sweet J (2002) Genetically modified organisms (GMOs): The significance of gene flow through pollen transfer, European Environment Agency, Copenhagen, pp 1-75

Fernandez-Cornejo J, Daberkow S, McBride WD (2001) Decomposing the size effect on the adoption of innovations: Agrobiotechnology and precision agriculture. AgBioForum 4: 124-136, http://www.agbioforum.org

Flannery M-L, Meade C, Mullins E (2005) Employing a composite gene-flow index to numerically quantify a crop's potential for gene flow: an Irish perspective. Environ. Biosafety Res. 4: $29-43$.

Ghislain M, Spooner DM, Rodriguez F, Villamon F, Nunez J, Waugh R, Bonierbale M (2004) Selection of highly informative and user-friendly microsatellites (SSRs) for genotyping of cultivated potato. Theor. Appl. Genet. 108: 881-890

Lawson HM (1983) True potato seed as arable weeds. Potato Res. 26: 303-306

McGill NP, Lohan G, O'Reilly B, Thorp C, Armstrong K, Gaule S, Macken F, Downey J, Dardis J, Devlin R, Leech B, McGloughlin T, Mullins E (2005) Coexistence of GM and non-GM Crops in Ireland. Report of the Working Group on the Coexistence of GM crops with Conventional and Organic Farming, Department of Agriculture and Food, Dublin, p 286

McHughen A (2006) Editorial - The limited value of measuring gene flow via errant pollen from GM plants. Environ. Biosafety Res. 5: 1-2

McPartlan HC, Dale PJ (1994) An assessment of gene transfer by pollen from field grown transgenic potatoes to nontransgenic potatoes and related species. Transgenic Res. 3: 216-225 
Milbourne D, Meyer R, Collins A, Ramsay L, Gebhardt C, Waugh R (1998) Isolation, characterisation and mapping of simple sequence repeat loci in potato. Mol. Gen. Genet. 259: 233-245

Murashige T, Skoog F (1962) A revised medium for rapid growth and bioassays with tobacco tissue cultures. Physiol. Plant. 15: 473-497

Ryan E, Meade C, Mullins E, Burke JI, Downes M (2006) Tracing field hybridisation in Ryegrass species using microsatellite and morphological markers. Environ. Biosafety Res. 5: 111-117

Skogsmyr I (1994) Gene dispersal from transgenic potatoes to conspecifics: A field trial. Theor. Appl. Genet. 88: 770-774

Slavov GT, Howe GT, Gyaourova AV, Birkes DS, Adams WT (2005) Estimating pollen flow using SSR markers and paternity exclusion: accounting for mistyping. Mol. Ecol. 14: 3109-3121

Tolstrup K, Andersen SB, Boelt B, Buus M, Gylling M, Holm PB, Kjellsson G, Pedersen S, Ostergard H, Mikkelsen SA (2003) Report from the Danish Working Group on the co-existence of genetically modifed crops with conventional and organic crops. DIAS Report Plant Production 94, p 275

Tynan JL, Williams MK, Conner AJ (1990) Low frequency of pollen dispersal from a field trial of transgenic potatoes. $J$. Genet. Breed. 44: 303-306

Wilkinson MJ, Davenport IJ, Charters YM (2000) A direct regional scale estimate of transgene movement from genetically modified oilseed rape to its wild progenitors. Mol. Ecol. 9: 983-991 